ARTIGO

Recebido em: 02/05/2016

Aceito em: 10/11/2016

\title{
Desafios para a biblioteca pública no processo de planejamento da formação e desenvolvimento do acervo
}

\section{Challenges for the public library regarding collection development}

\author{
Ana Cláudia Carvalho de MIRANDA (anaclaudia@tjrn.jus.br)* - Mônica Marques \\ Carvalho GALLOTTI (monica_mcg@hotmail.com)** - Adriano CECATTO \\ (adrianocecatto@gmail.com)*** \\ * Chefe da Biblioteca do Tribunal de Justiça do Estado do Rio Grande do Norte \\ ** Professora da Universidade Federal do Rio Grande do Norte \\ *** Doutorando em História pela Universidade Federal de Minas Gerais
}

\begin{abstract}
Resumo
Aborda um recorte histórico sobre a importância da biblioteca pública para a sociedade bem como os desafios enfrentados no desenvolvimento das coleções por este tipo de biblioteca. Os desafios para as bibliotecas públicas são muitos, dentre estes, a escassez de recursos financeiros, trazendo dificuldades para um exercício eficaz de seu papel social perante a comunidade. Nesse sentido, o planejamento de ações em torno da disponibilização de informação se torna algo de fundamental importância. 0 presente artigo propõe uma reflexão sobre o desenvolvimento de coleções e os desafios presentes no gerenciamento das coleções em bibliotecas públicas. As coleções são geridas com vistas a propor uma ordem para se tentar domar o aglomerado de itens informacionais. Estes itens são analisados, organizados e sistematizados nos acervos com base em planejamento e critérios e diretrizes sólidas, com intuito de proporcionar um crescimento racional e equilibrado. Por meio da revisão de literatura, verificaram-se alguns desafios e perspectivas sobre a prática de formar e desenvolver coleções no âmbito das bibliotecas públicas na contemporaneidade, as quais atuam como disseminadoras do conhecimento, constituem um espaço voltado para as atividades de promoção de leitura, cultura, cidadania, inclusão social e lazer. Neste sentido, são expostas algumas ações fundamentais em prol da formação e expansão das coleções, que corresponda às reais necessidades de informação do público alvo.
\end{abstract}

Palavras-chave: Biblioteca pública. Gestão de coleções. Política de desenvolvimento de coleções. Formação e desenvolvimento de coleções.

\begin{abstract}
This work deals with a historical approach regarding the importance of the public library for society as well as some challenges faced regarding collection management. The challenges for public libraries are many, among them, the shortage of funds impeding an effective exercise of their social role in the community. Thus, planning actions around the provision of information becomes something of fundamental importance. This article aims to propose a reflection regarding collection development and challenges presents in collection management on behalf of public libraries. Collections are managed aiming order as well as to tame excess informational items. These items are analyzed, organized and systematized in collections based on planning solid criteria and guideline, aiming to provide a rational and balanced growth of the collection. A literature review on the subject was done and it points out all the necessary perspective regarding contemporary collection development in public libraries. It was seen that public libraries act as knowledge disseminators. The public library is a sphere that helps to promote reading, culture, citizenship, social inclusion and leisure. In this sense, the research exposes some fundamental actions for the formation and expansion of the collections done in order to corresponds to the real information needs of the target audience.
\end{abstract}

Keywords: Public library. Collections management. Collection development policy. Collection development.

v. 22, n. 48,2017

p. $15-26$

ISSN 1518-2924 


\section{INTRODUÇÃo}

No atual contexto de crescimento exponencial na produção de novos conhecimentos, a sociedade da informação é assinalada pelo fluxo constante de informações gerando um enorme volume informacional e do desenvolvimento tecnológico, podendo assim, atuar nas várias áreas do conhecimento, contribuindo na tomada de decisão nos diferentes grupos sociais.

As bibliotecas, sobretudo as públicas, objeto desta discussão, tem como objetivo possibilitar o acesso à informação a todos os cidadãos, de diferentes culturas e grupos. Conforme a intelecção de Dias e Pires (2003), o fornecimento de informações é a principal função social dos serviços de informação. Le Coadic (2004, p.4) define informação como "um conhecimento inscrito (registrado) sob a forma escrita (impressa ou digital), oral ou audiovisual, em um suporte". Na mesma perspectiva, Cunha e Cavalcante (2008) compreendem a informação como um registro do conhecimento que pode ser relevante para direcionar uma decisão.

A informação empregada, nesse cenário, compreende diversos tipos de formatos informacionais: artigos de periódicos, jornais, monografias, dissertações, teses, relatos de experiências, obras de referências (atlas, dicionários, enciclopédias etc.), materiais especiais (fotos, partituras musicais, atlas etc.), documentos eletrônicos (bases de dados, e-books, portal de periódicos eletrônicos, repositórios digitais de informação, revistas digitais), etc.

Nas últimas décadas, a informação se tornou a mais poderosa força de transformação do indivíduo, estando presente no cotidiano da sociedade por meio das relações sociais, econômicas e culturais e, adquirindo, neste sentido, um caráter decisivo para o alcance da cidadania, das metas e dos objetivos propostos pelo ser humano, que criou vínculos de dependência com a informação visando à sua melhor adaptação ao meio em que vive. A informação para ter qualidade é preciso ser relevante, confiável, atual, acessível, precisa, oportuna e deve ser ajustada às demandas e expectativas dos usuários. 0 valor da informação está associado à utilidade que ela apresenta ao público ao qual se destina.

A informação ao longo dos anos tem adquirido uma característica de mercadoria, ou seja, algo que pode ser capitalizado e que proporciona diversidade de oportunidades; enquanto mercadoria, assume força de poder.

Quanto à formação da coleção de biblioteca, o diferencial se dá pela filtragem adequada das informações obedecendo a padrões estabelecidos de seleção que garantam a disponibilidade de obras confiáveis nos diversos suportes informacionais. Assim, é imprescindível conhecer as necessidades da comunidade, principalmente para a biblioteca pública, a fim de permitir um planejamento com qualidade e eficácia no desenvolvimento e formação das coleções.

Na perspectiva de Dias e Pires (2003), a visão atual da biblioteca como centro ou unidade de informação difere de sua ideia convencional. Essa mudança se originou da valorização da informação em todos os campos de atividades no mundo contemporâneo. A informação é considerada por autores das diversas áreas do conhecimento como "recurso indispensável" e, no entanto, deve estar à disposição e a serviço de todos: sociedade, instituições, indivíduos etc.

Desta forma, o texto inicia conceituando e historicizando a biblioteca pública, suas atribuições no processo de desenvolvimento da informação. Em seguida, trataremos das políticas de desenvolvimento do acervo, tendo como foco os seus usuários.

\section{BIBLIOTECA PÚBLICA}

No Brasil, a biblioteca pública teria surgido no inicio do século XIX, sendo a primeira inaugurada em Salvador-BA (1811. Antes disso, predominavam bibliotecas mantidas por ordens religiosas (SILVA, 2013). Nesse período imperial, havia limitado acesso aos livros e controle dos portugueses sobre o material impresso.

Posteriormente foram criadas várias bibliotecas públicas em diferentes Estados, porém caracterizaram-se pela carência de infraestrutura. "Locais improvisados, acervo desatualizado e composto de doações, instalações precárias e carência de recursos humanos adequados eram as características dessas instituições." (SILVA, 2013, p.17). Soma-se a isso o 
problema do analfabetismo, incluindo $80 \%$ da população, além de um modelo de biblioteca europeia, portanto, fora da realidade brasileira.

Para Santos e Santos (2012), a história das bibliotecas públicas no Brasil remetem à história da Fundação Biblioteca Nacional (FBN), que teve seu desenvolvimento a partir de coleções trazidas de Portugal pela família real em 1808. Nesse contexto, podemos levar em consideração que a própria história ensinada no período imperial foi a europeia, embora houvesse iniciativas para se constituir uma história do Brasil a partir das pesquisas do Instituto Histórico e Geográfico Brasileiro (IHGB).

No inicio do século XX, principalmente com a Semana de Arte Moderna de 1922, realizada em São Paulo, buscou-se dar uma identidade própria à cultura brasileira. A partir da década de 1930, ampliaram-se as bibliotecas públicas pelo país, destacando-se como marco político a criação do Instituto Nacional do Livro (INL), em 1937, por Getúlio Vargas, que também soube criar estratégias a partir de uma narrativa que pudesse constituir a sua imagem como o ideal político do Estado, tendo o livro como mecanismo de disseminação e propagação de seus ideais. No entanto, na década de 1940, as bibliotecas públicas brasileiras se caracterizavam por serem depósitos de livros.

Porém, foi na segunda metade do século XX, tendo como marco a Reforma do Ensino de 1971 (Lei no 5.692), que possibilitou a ampliação e democratização da escola brasileira, e conseqüentemente, surgiu a necessidade de bibliotecas nas escolas a partir de políticas governamentais de educação e cultura, sendo fundamental para os estudantes e a população geral. No entanto, ainda se caracterizavam muito precárias. Segundo Milanesi (2013, p.63), "acervos precários e desorganização quase sempre estiveram juntos. As bibliotecas públicas não dispunham e não dispõem de competência profissional para organizá-las".

A partir da década de 1990 ocorreu a extinção do Instituto Nacional do Livro, transferindo as atribuições à Biblioteca Nacional. Nessa mesma década o surgimento da internet possibilitou outras formas de acessar a informação, e a biblioteca pública deixou de ser referência. Com o Manifesto da UNESCO (1994), divulgaram-se princípios universais para as bibliotecas públicas, tornando claras as suas funções: informar, educar, alfabetizar e cultura, incorporando as novas tecnologias digitais. (SILVA, 2013). Conforme Bernardino e Alentejo (2013, p.47), "a biblioteca tem se tornado uma instituição democrática, de fonte universal de acesso à informação e de socialização do conhecimento dentro do que se convencionou ser chamado de Sociedade da Informação".

0 surgimento inicial dessas instituições teve o intuito de manter, preservar e guardar a memória dos registros do conhecimento, mas com o passar do tempo foram se diversificando em conformidade com o contexto de inserção da comunidade. Diante desse panorama e evolução, as bibliotecas foram ganhando novas funções. Segundo Cesarino (2007, p. 11), "são instituições muito antigas que sobrevivem há anos, adaptando-se às diversas mudanças políticas, sociais e tecnológicas. Essa sobrevivência, por si só, já é suficiente para provar que cabe à biblioteca uma função muito importante na sociedade". Para Prado (1992, p. 21), as bibliotecas públicas "são instituições básicas para o processo de educação, cultura e informação de um povo. Seus objetivos principais são: estimular, nas comunidades, o hábito de leitura e preservar o acervo cultural". Neste sentido, é disseminadora do conhecimento e um espaço voltado para as atividades promovendo leitura, cultura, cidadania, inclusão social e recreacional (lazer).

Conforme Bernardino e Alentejo (2013), as bibliotecas públicas devem priorizar o acesso à informação, implicando em compreender sua missão e funções com a sociedade e um gerenciamento proativo e dinâmico. É uma organização com uma missão bastante desafiadora, entretanto, é preciso atuar fornecendo informações confiáveis para seu público. Contribuindo com essa reflexão, Palleta et. al. (2015) dizem que para o cumprimento de tal missão, é preciso empregar estratégias que facilitem a realização dos serviços de maneira satisfatória.

Entretanto, essas instituições enfrentam uma crise, deixando de cumprir seu papel prioritário que é de ser difusora da informação e da cultura. Contudo, a explosão informacional e o acelerado desenvolvimento das tecnologias trazem grandes desafios às bibliotecas públicas. Assim sendo, faz-se necessário a essa instituição rever o cumprimento de sua missão com a comunidade a qual está inserida, visto que possuem o papel social de socialização do conhecimento, disponibilizando prontamente para os seus usuários todo tipo de conhecimento. 
Neste sentido, o cenário brasileiro evidencia o descaso e negligência com as bibliotecas públicas por falta de orçamento para investir na ampliação dos acervos e numa infraestrutura apropriada frente aos avanços tecnológicos com recursos audiovisuais. De acordo com Machado e Suaiden (2013), o desenvolvimento das tecnologias e as novas relações oriundas destas, têm proporcionado mudanças na concepção das bibliotecas e impõem diversificação dos papéis. Contudo, Bernardino e Susiden (2011) evidenciam que as bibliotecas públicas brasileiras, na atual conjuntura, ainda não detêm equipamentos tecnológicos apropriados para disseminar o uso das novas tecnologias.

Para isso, precisam de investimentos e de políticas para transformar as bibliotecas num ambiente adequado e com condições para realizarem suas atividades de acesso ao conhecimento, como um espaço de democratização do conhecimento e de ações culturais buscando atender as necessidades de informação do seu público alvo. Nestes termos, estas unidades de informação precisam estabelecer um planejamento para formação, crescimento e manutenção de seus acervos, contando com o apoio dos órgãos governamentais ligados à educação e à cultura, com o propósito de terem suas coleções sempre adequadas à satisfação de seus usuários.

\section{PROCESSO DE DESENVOLVIMENTO DE COLEÇÕES}

O contexto social atual é caracterizado por um fluxo intenso e acelerado da informação. Eventos como o advento da imprensa aliado à evolução das novas tecnologias da informação e comunicação (TICs) contribuíram para o aumento vertiginoso da produção e circulação do conhecimento. Porém, os orçamentos escassos, impossibilitam o atendimento a todas as demandas e necessidades informacionais da clientela com recursos próprios, algo que se constitui como um fator limitante para que o conhecimento seja disseminado. Isso faz com que seja necessária a realização de um planejamento eficiente para o crescimento dos acervos, de forma a tornar o processo de desenvolvimento das coleções algo essencial.

Na perceptiva de Miranda (2004, p.141) o ato de desenvolver coleções "[...] implica sistematizar e criar procedimentos para seleção, aquisição, avaliação e desbastamento do acervo". Já Cunha e Cavalcanti (2008) definem desenvolvimento de coleções como um planejamento para aquisição de acordo com os interesses dos usuários, podendo englobar a avaliação sistemática do tamanho e da utilidade do acervo em relação aos objetivos da biblioteca, dos usuários e da organização à qual a biblioteca está inserida. 0 desenvolvimento de coleções pressupõe um processo, não possuindo começo, meio ou fim, sendo permanente, e todas as etapas possuem o mesmo grau de relevância. Nesse sentido, torna-se importante para uma biblioteca o processo de catalogação, classificação e indexação.

No entendimento de Dias, Silva e Cervantes (2013), o procedimento de desenvolver coleções em bibliotecas públicas constitui em processos de formar e administrar acervo para atender as necessidades de informação pertinentes ao seu público alvo. Desta maneira, para o melhor desenvolvimento da coleção é preciso ter por referência um plano preestabelecido que garanta sua continuidade e adequação necessária à formação do acervo para documentos nos variados formatos. Cabendo ao profissional da informação, gestor da biblioteca pública, organizar a coleção de modo a evoluir equilibradamente em todas as áreas do conhecimento empregadas na formação do acervo, a fim de impossibilitar que o mesmo cresça desacertadamente, sem metas e disponibilizar acesso igualitário dos materiais para a comunidade, no suporte apropriado, deixando ao alcance dos seus usuários o patrimônio cultural de sua sociedade. Dessa forma, contribuirá não somente na guarda de seu registro, quanto na obtenção das obras que reflitam as tendências atuais e os avanços da sociedade.

O processo de desenvolvimento de coleções deve considerar as necessidades da comunidade de forma abrangente. Em contrapartida, não pode confundir as solicitações dos usuários mais assíduos com as dos usuários em sua totalidade.

A importância do processo de desenvolvimento de coleções é apresentada por Vergueiro (1989), sendo tratada como atividade que requer planejamento, além de ser ininterrupto, sistêmico e cíclico, as atividades referentes ao acervo não devem ser executadas isoladamente, por ser uma tarefa presente no cotidiano das unidades de informação, respeitando os objetivos e o público alvo da biblioteca, a fim de garantir aos usuários terem à sua disposição uma variedade de opções com novas obras para atender as 
solicitações. E, na biblioteca pública é tido como uma atividade bastante complexa, por atender tanto necessidades escolares, utilitárias, bem como estimula atividades recreativas.

Dias, Silva e Cervantes (2012) chamam a atenção sobre como o surgimento dos documentos eletrônicos expandiram as formas de acesso e recuperação da informação. Convém ressaltar que esse episódio adicionou novos desafios na produção e execução da política de desenvolvimento de coleções.

O desenvolvimento de coleções no formato eletrônico tem gerado grandes mudanças neste processo por contribuir para um maior crescimento e variedade do acervo, permitindo ainda um melhor aproveitamento dos recursos financeiros disponibilizado para aquisições. Contudo, vale salientar que o acesso aos documentos eletrônicos requer equipamentos apropriados para seu manuseio, requerendo, por parte do público usuário, qualificação para utilizá-los.

Além disso, o processo de desenvolvimento e formação do acervo possui uma função crucial na biblioteca. Cabe ao bibliotecário ser cauteloso e imparcial no tocante às atividades inerentes a este processo, levando em consideração alguns critérios: estudo da comunidade, seleção, aquisição, manutenção, avaliação, descarte e armazenamento.

Sendo assim, para execução do processo como um todo, faz-se necessária a elaboração e adoção de parâmetros mediante a criação de critérios que garantem a qualidade no gerenciamento da tomada de decisão destinada à inserção ou à exclusão definitiva das obras pertencentes ao acervo.

\section{POLÍTICA DE FORMAÇÃO E DESENVOLVIMENTO DO ACERVO}

Em relação à política de desenvolvimento e formação do acervo, Cunha e Cavalcanti (2008) definem como um conjunto de critérios, consubstanciados num documento, objetivando garantir o crescimento racional e equilibrado de uma coleção ou acervo específico. Conforme Dias, Silva e Cervantes (2012, p. 49), a política de desenvolvimento de coleções "constitui a pedra fundamental de todo acervo, seja ele físico ou eletrônico, e é evidente que essa está sofrendo alterações significativas em sua composição". Por sua vez, busca nortear a formação e expansão do acervo, com base nos objetivos da biblioteca, nas necessidades de informação da comunidade a ser assistida, orçamento e outros recursos informacionais disponíveis (consórcios entre bibliotecas).

Na concepção de Vergueiro (1989), a política contribuirá no estabelecimento de diretrizes para a tomada de decisão dos bibliotecários em relação à escolha da publicação a ser introduzida à coleção, como também a administração dos recursos informacionais. A política proporcionará um retrato do cenário do estado geral do acervo, contribuindo para atingir os objetivos institucionais e fornecer subsídios aos bibliotecários, para que possam apresentar às autoridades superiores suas solicitações e reivindicações para aquisição de novas obras, que - em se tratando de biblioteca pública -, requerem apoio manutenção e preservação da memória da comunidade em que a mesma está inserida.

Assim, na elaboração da política, Miranda (2007) propõe ao bibliotecário ter ciência de alguns dados indispensáveis para apreciação: o estado atual da coleção, quais áreas do conhecimento são mais solicitadas, o perfil das necessidades informacionais da clientela e os objetivos da instituição à qual a biblioteca está agregada.

Tanto Vergueiro (1989) como Dias e Pires (2003) recomendam uma comissão para a elaboração da política, composta pelo bibliotecário, profissionais envolvidos com a biblioteca, usuários, assessores e no caso da biblioteca pública, um representante do conselho comunitário, devidamente analisada e nomeada pelos órgãos competentes, visando assegurar a representatividade da comunidade nas atividades do serviço de informação, auxiliando para uma ampliação coerente, lógica, equitativa e equilibrada do acervo.

Desta maneira, cabe à comissão o dever de se comprometer em: garantir que os objetivos institucionais estejam presentes no planejamento da formação da coleção; determinar as prioridades da biblioteca; estabelecer os parâmetros do acervo, inclusive acervos especiais e coleções para certas situações, como documentos multiculturais, obras para alfabetização e recursos destinados a pessoas com necessidades especiais, com vistas a garantir acesso igualitário aos usuários; permitir continuidade e estabilidade nos procedimentos da biblioteca ao passo que o quadro de pessoal da biblioteca pode ser renovado, contudo os procedimentos não serão alterados, por estarem registrados na 
política; promover o acesso aos recursos eletrônicos inclusive o acesso em linha a periódicos, bases de dados e outros suportes de fontes de informação; planejar a administração dos recursos avaliando as necessidades presentes e futuras do acervo; contemplar áreas de maior demanda pela comunidade, definindo as prioridades de seleção; fixar extensão e profundidade na cobertura temática da coleção, segundo os diferentes níveis da comunidade a ser atendida; definir critérios para preservação e conservação das publicações (encadernação e restauração, etc.); estabelecer normas para duplicação de documentos; determinar critérios para recebimento de doações e descartes; promover a reavaliação periódica da coleção, a fim de decretar quando e sob quais condições o documento será remanejado e descartado do acervo; revisar e avaliar periodicamente a política (VERGUEIRO, 1989).

Contudo, a elaboração da política requer um minucioso e contínuo estudo, que servirá como diretriz para instituir as estratégias de ações organizacionais e atuar como instrumento delimitador de critérios na tomada de decisão e na alocação de recursos para formação e expansão do acervo, além de orientar os procedimentos essenciais para compra por licitação. Vale salientar, que a implementação de políticas de desenvolvimento e formação do acervo é da responsabilidade do bibliotecário.

Dentre as etapas do desenvolvimento e formação do acervo, uma das mais relevantes para assegurar que a coleção esteja de acordo com as necessidades da comunidade, sem deixar de incluir acesso às pessoas com deficiência, e oferecer a igualdade de oportunidades para todos, é o estudo da comunidade.

\section{ESTUDO DE COMUNIDADE}

É um processo em que se busca analisar mais de perto os aspectos sociais, educacionais, econômicos, culturais e outras características inter-relacionadas da comunidade onde a biblioteca está localizada. Nesse sentido, constitui uma tarefa de pesquisa indispensável para este tipo de biblioteca, devendo ser realizada periodicamente, perante sua comunidade, a fim de acompanhar as transformações no seu perfil, requerendo para esse fim específico um grupo qualificado.

Na concepção de Weitzel (2006, p.21), os estudos de comunidade "são instrumentos importantes para a administração de bibliotecas de modo geral e para o processo de desenvolvimento de coleções em particular", por retratar o perfil e as necessidades de informação da sociedade local e contribuir para um planejamento eficaz no tocante ao desenvolvimento e formação das coleções.

Para a biblioteca pública, seu público alvo a ser pesquisado são todas as pessoas que residem na mesma jurisdição política servida por ela. Ao realizar o diagnóstico, os dados relevantes para o conhecimento da comunidade são: históricos, demográficos, geográficos, educativas, sociais, econômicas, transportes, culturais e políticas.

No entendimento da IFLA (2012), torna-se relevante definir quem utiliza e quem não utiliza os serviços oferecidos pela biblioteca. Tomando por base os dados coletados e analisados do estudo de comunidade, a biblioteca terá suporte para estabelecer as prioridades para selecionar os documentos a serem incorporados ao acervo, fundamentado nas necessidades dos clientes reais e potenciais diagnosticados, considerando sua capacidade de acesso a serviços alternativos. Por fim, estes dados fornecem uma caracterização do público alvo.

\section{PROCESSO DE SELEÇÃO DO ACERVO}

0 marco das transformações ocorridas na sociedade da informação, mediante o enorme volume na produção científica, tornou o processo de seleção bastante criterioso e intelectual para preservar e garantir um crescimento equilibrado e coerente do acervo, devendo ser executada por um profissional competente no assunto tratado, em sintonia com as sugestões dos usuários.

0 processo de seleção da coleção é uma atividade de comparação das diversas publicações disponíveis no mercado editorial sobre um assunto, julgando o valor do material isoladamente para os usuários, apreciando mediante as necessidades da comunidade 
fundamentada na aplicação de princípios éticos e instrumentos para melhor aplicação dos recursos financeiros, buscando desse modo impedir desperdícios dos investimentos.

A execução adequada nesse processo, de acordo com Figueiredo (1991), garantirá a qualidade e o tamanho do acervo em concordância com as necessidades informacionais dos usuários. No entendimento de Muller (2000, p. 24), "a política de seleção do acervo deve ser muito bem planejada e suplementada por esquemas de cooperação com outras bibliotecas". Uma boa seleção permitirá que o acervo se mantenha com padrão excelente.

Na perspectiva de Miranda (2007), este procedimento na seleção é imprescindível, tendo em vista que de nada valeria dispor de uma vasta coleção, mas imprópria aos usuários, pois, sem eles, a biblioteca seria apenas um depósito de publicações e deixaria de exercer sua finalidade de organizar, processar, indexar e disseminar o conhecimento, criando meios para proliferação e difusão do saber para gerações futuras.

Nesse contexto, a IFLA (2012) evidencia que grandes acervos não significam que a coleção seja de boa qualidade, principalmente neste mundo globalizado, em que os documentos digitais e eletrônicos crescem de forma exponencial, ou seja, a importância da coleção para as necessidades da comunidade local é mais relevante do que sua dimensão espacial. 0 tamanho do acervo é estabelecido por diversos fatores que influenciam na seleção, como espaço físico, recursos financeiros, população da área de atuação da biblioteca, proximidade com outras bibliotecas, função regional do acervo, acesso a suportes eletrônicos, avaliação das necessidades locais, percentual de aquisição e descarte, e política de intercâmbio de obras com outras bibliotecas da rede biblioteca pública.

A sociedade contemporânea passa por avanços do conhecimento científico e tecnológico, ocasionando profundos impactos e desafios para o bibliotecário conhecer os materiais de interesse dos usuários, lançados no mercado editorial, devendo recorrer a diversas fontes de informação para auxiliá-lo na seleção. De acordo com o tipo de biblioteca, podem variar os instrumentos que são utilizados, entre eles destacam: catálogos de editores, prospectos de lançamentos, anúncios, sites das editoras; eventos e feiras de livros; bibliografias e listas de materiais recomendados; lista de reserva; resenhas críticas por revisores qualificados; guias que elencam publicações periódicas; e publicadas em periódicos especializados.

O bibliotecário, para executar a seleção, não pode se limitar em adotar apenas um dos instrumentos, pois quanto maior sua variedade empregada neste processo, mais informações essenciais para conduzir a escolha das obras para composição do acervo, mesmo sendo uma biblioteca pública que possui uma coleção bastante abrangente nas diversas áreas do conhecimento.

Para assegurar a qualidade nas publicações a serem adquiridas, é preciso que sejam determinados critérios para esse processo, devendo contemplar dois fatores decisivos: o interesse da comunidade a ser servida e os recursos financeiros destinados para a aquisição.

0 estabelecimento de critérios, segundo Miranda (2007), garante que o acervo seja produto de um planejamento voltado para as diretrizes e objetivos da comunidade local. Seguem alguns dos critérios adotados: adequação do material aos interesses da comunidade onde a biblioteca está inserida; autoridade do autor e/ou editor; atualidade técnico-científica dos conteúdos; disponibilidade para acessar os documentos em suporte digital; escassez de material sobre o assunto na coleção da Biblioteca; aparecimento do título em bibliografias e índices; cobertura/tratamento; custo justificado; idioma acessível; relevância/interesse acadêmico-científicos; número de usuários potenciais que poderão utilizar o material; e condições físicas do material.

Os critérios apresentados anteriormente são apenas sugestão e nem sempre são adotados em todas as publicações, sendo necessário um ajuste para cada biblioteca, conforme a sua realidade e seus objetivos. Uma das etapas subsequentes é a do processo de aquisição.

\section{PROCESSO DE AQUISIÇÃO DO ACERVO}

O processo de aquisição é o cumprimento das decisões tomadas na etapa anterior. É o procedimento relativo à incorporação das publicações adquiridas por meio das seguintes modalidades: compra, permuta e doação. A execução desse mecanismo exige um empenho 
maior por parte do profissional encarregado devido aos trâmites das compras no setor público serem realizadas normalmente a partir de licitações.

Em se tratando da aquisição por meio de doação ou permuta, é menos detalhista, por requerer menor esforço do profissional responsável, mas segundo Miranda (2007), todos os documentos originários destas modalidades precisam ser avaliados antes de inseri-los ao acervo, a fim de evitar ter uma coleção imensa e fora do perfil dos interesses da comunidade de usuários.

Nesse sentido, Andrade e Vergueiro (1996, p.6) argumentam sobre a complexidade das atividades relativas à aquisição por compra:
À aquisição caberá o trabalho minucioso de identificação, localização dos itens e sua posterior obtenção para o acervo, qualquer que seja a maneira de tornar isto possível. E não é uma tarefa assim tão automática, pois, infelizmente para os profissionais, os títulos selecionados não se encontram acenando para eles ao dobrar da esquina, a gritar 'olha eu aqui, olha eu aqui' e quase implorando para serem adquiridos. Muitas vezes, realizar um trabalho de aquisição assemelha-se a procurar uma agulha em palheiro, tantas são as possibilidades e dificuldades existentes. É uma atividade que exige perseverança e atenção a detalhes, de maneira a evitar um descompasso entre o que foi escolhido em primeiro plano para aquisição e aquilo que chega às mãos do usuário.

0 processo de aquisição compreende dois elementos essenciais: orçamento e alocação de verbas. Inicialmente, devem ser estabelecidos os recursos financeiros para consentir um panorama da realidade do que se pode contar. Segundo Andrade e Vergueiro (1996), na execução, o orçamento prognosticado para obtenção das publicações raramente equivale aos recursos disponibilizados. Dessa forma, impossibilitando que todas as necessidades consideradas prioritárias sejam supridas.

Conforme o primeiro censo nacional das bibliotecas públicas municipais (BPMs) realizado pela Fundação Getúlio Vargas (FGV), encomendada pelo Ministério da Cultura (MINC), em setembro/novembro de 2009, revelou o perfil das instituições em todo país, possuía 4.763 bibliotecas públicas em 4.413 municípios. No qual foram pesquisados todos os 5.565 municípios brasileiros, o que significa que 1.152 cidades brasileiras não dispõem de nenhuma biblioteca.

A pesquisa mostra que entre as bibliotecas em funcionamento a forma de aquisição predominante para acervo para as BPMs tem sido $83 \%$ por doação e apenas $17 \%$ por compra. Os resultados desta pesquisa demonstram a dura realidade das bibliotecas públicas brasileiras no sentido de desenvolver acervos públicos que reflitam os desejos e interesses da comunidade. Sendo uma raridade encontrar bibliotecas que conseguem preservar, manter e ampliar um acervo para a sua comunidade adquirindo obras, apenas por doações voluntárias.

Neste sentido, considerando dados da pesquisa, Freitas e Silva (2014) ressaltam que acervos desatualizados, mal conservados e desconexos com as necessidades de informação da comunidade local pouco atraem os usuários, pois eles sabem que não encontrarão nas estantes da biblioteca as respostas para os seus questionamentos. Normalmente, os livros compõem a quase totalidade do acervo. Entretanto, os recursos tecnológicos e audiovisuais ainda não foram aproveitados como deveriam, na perspectiva de Milanesi $(1988$, p. 63) biblioteca pública é sinônimo de museu de livros por apresentar coleção morta, quase totalmente inútil.

Na percepção de Silva (2013), a aquisição de e-books comerciais, é um grande desafio que se impõe aos bibliotecários, tendo em vista que este tipo de materiais possui mais restrições em seus modelos de negócios que os livros impressos, porém nesse tipo de unidade de informação em questão a situação ainda é indefinida.

Com isso, acaba sendo difícil e meramente impossível manter um acervo atualizado, além de se desenvolvendo em conformidade com o crescimento do mercado editorial.

Para mudar este cenário, Freitas e Silva (2014) recomendam que se destine um orçamento fixo para a administração das bibliotecas. Esta verba serve para comprar livros, investir em programas de leitura, assinar bases de dados e periódicos, disponibilizar produtos e serviços online, atendendo as necessidades de informação dos usuários locais e remotos. Todos esses recursos contribuem para que a biblioteca preste um serviço de boa qualidade aos seus usuários. 
Considerando-se todos os fatores anteriormente mencionados, percebe-se que o processo de aquisição é a concretização das decisões tomadas na seleção, objetivando renovar e melhorar o acervo em conformidade com os dados de uso e o diagnóstico obtido no estudo de comunidade.

\section{PROCESSO DE AVALIAÇÃo DO ACERVO}

Neste procedimento são determinados padrões, justificados em medidas ou números para avaliar o nível do acervo. Portanto, a avaliação da coleção deve ser sistemática e compreendida como um processo adotado para estabelecer a relevância e ajuste do acervo com base nos objetivos da biblioteca pública, permitindo traçar critérios quanto à aquisição, à acessibilidade e ao descarte.

De acordo com Cunha e Cavalcanti (2008), a avaliação da coleção é apresentada como mensuração quantitativa e qualitativa do acervo de uma biblioteca em relação ao nível de atendimento das necessidades dos usuários. A metodologia empregada para avaliar a coleção pode ser: quantitativa (tamanho e evolução) ou qualitativa (julgamento por especialistas, análise do uso real), em que os resultados são confrontados e ponderados, certificando a obtenção dos objetivos da avaliação da coleção, assegurando uma política de desenvolvimento de coleções com qualidade e credibilidade.

Referente à avaliação qualitativa, a apreciação é executada por especialistas num assunto, podendo provocar alguns problemas, segundo salienta Lancaster (1996): o especialista talvez não seja totalmente imparcial, como também, não está familiarizado com a comunidade que a biblioteca atende.

Portanto, a avaliação contribui diretamente no aperfeiçoamento do processo de seleção. Além de se fazer necessária, pois ela conduz qualquer mudança, transformação, preservação e, até mesmo, o descarte das publicações, como o fim das assinaturas dos periódicos. Indica não somente a necessidade de restruturação da coleção, como também estabelece um planejamento com as alterações a serem tomadas.

\section{DESBASTAMENTO DE DOCUMENTOS}

Compreende-se por desbastamento a eliminação do acervo ativo, títulos e/ou exemplares, partes de coleções, seja para remanejamento, descarte ou conservação (restauração). É um processo permanente e sistemático, objetivando garantir a qualidade da coleção. Assim sendo, o desbastamento, não consiste exclusivamente na exclusão das publicações não convencionais, demandando ao bibliotecário maior atenção e dedicação ao analisar o material.

Cunha e Cavalcanti (2008) definem descarte como uma operação que consiste separar ou retirar do acervo de uma biblioteca os documentos supérfluos, antiquados ou que se encontram sem condições de uso. Os documentos removidos do acervo precisam ser registrados no inventário, dando-se baixa no livro de tombo da biblioteca. 0 descarte libera espaço para novas obras e contribui para assegurar a qualidade geral da coleção.

A biblioteca pode adotar três tipos de descarte, conforme o entendimento do responsável: retirada do acervo e transportado para um acervo reserva (depósito), eliminação do acervo e oferecido como doação a outras bibliotecas, e por último, excluir definitivamente a obra após uma rigorosa e profunda avaliação

Vergueiro (1989, p.75) evidencia a atividade pertinente ao desbastamento, requerendo mais cautela, responsabilidade e segurança, por parte do bibliotecário:

Afinal - pergunta-se ao bibliotecário -, quando se descartar? E para quê? São perguntas que, deve-se reconhecer, constituem reais dilemas para profissionais que tiveram toda uma educação (não apenas a superior) para conservar os materiais informacionais, sob sua responsabilidade, da melhor forma possível, a fim de que pudessem vir a ser utilizados pela coletividade - ou, ao menos, conservados para uma geração futura.

Dessa forma, Miranda (2007) recomenda que se apliquem as mesmas diretrizes adotadas no processo de seleção, no instante da apreciação do descarte das publicações pela comissão responsável, pois do mesmo modo como seleciona as obras que serão incluídas na 
coleção, também é indispensável que sejam avaliados os favoráveis à exclusão definitiva do acervo.

\section{CONSIDERAÇõES FINAIS}

Conforme as reflexões apresentadas, este trabalho evidenciou que a biblioteca pública é uma instituição que possui sua história marcada por diversas crises e desafios, influenciados por fatores que contribuíram para o seu avanço ou retrocesso. Dentre eles, podemos mencionar o investimento por parte das autoridades locais e nacionais na educação, cultura, lazer e políticas públicas governamentais. Contudo, ao longo de sua trajetória, algumas dificuldades persistem e comprometem o papel desempenhado pela biblioteca apresentando um panorama precário.

As bibliotecas públicas, como espaço social, são instrumentos disseminadores de informação e conhecimento para a comunidade na qual estão inseridas, sendo, assim, um meio de democratização da leitura e do conhecimento para um país.

Diante do constante avanço das tecnologias da informação, os desafios para essas bibliotecas são ainda maiores. No entanto, o desenvolvimento tecnológico contribui para ampliar as desigualdades sociais. Tais pontos tomam proporções ainda mais amplas por questões relacionadas ao desenvolvimento econômico, político e cultural do Brasil.

$\mathrm{Na}$ atual conjuntura, muitas são as barreiras e desafios ao se comentar a intensidade com que a informação se multiplica, possibilitando a produção de novos conhecimentos nos diferentes suportes. Em virtude do grande volume informacional, surge o desafio de manter uma coleção adequada e atualizada que atenda a demanda e as necessidades do público.

Em relação ao processo de planejamento da formação e desenvolvimento do acervo para garantir a qualidade da informação, concluímos que a política de coleção é muito importante para nortear as ações na aquisição de novos materiais informacionais.

Nessa perspectiva, o desenvolvimento de coleções deve ser um processo ininterrupto, permanecendo em constante evolução. Entretanto, é necessário compor uma política de desenvolvimento da coleção que conglomere os objetivos destinados às necessidades de informação da comunidade à qual está inserida a biblioteca, com a finalidade de subsidiar a tomada de decisão no processo de seleção, considerando todos os fatores relevantes aos interesses da comunidade, como também avaliar a coleção periodicamente para preservar a qualidade e a idoneidade do acervo.

\section{REFERÊNCIAS}

ANDRADE, D.; VERGUEIRO, W. Aquisição de materiais de informação. Brasília: Briquet de Lemos, 1996.

BARRETO, A. A. A questão da informação. Disponível em: <http://aldoibct.bighost.com.br/quest/quest2.pdf>. Acesso em: 12 jan. 2016.

BERNARDINO, M. C. R.; SUAIDEN, E. J. Imagem da biblioteca pública na Sociedade da Informação. InCID: Revista de Ciência da Informação e Documentação, Ribeirão Preto, v. 2, n. 1, p. 130-142, 2011.

; ALENTEJO, E. da S. Perfil tecnológico das bibliotecas públicas no Brasil e na Europa: estudo sobre a democratização do acesso à informação e ao conhecimento em bibliotecas do Brasil, Espanha e Alemanha. Revista Digital de Biblioteconomia e Ciência da Informação, Campinas, v.11, n.3 p.46-71, 2013. Disponível em:

<http://www.sbu.unicamp.br/seer/ojs/index.php/rbci/article/view/3880>. Acesso em: 30 jan. 2016.

BRASIL. Ministério da cultura. Censo nacional das bibliotecas públicas municipais.

Brasília: Minc, 2009. Disponível: < http://www.cultura.gov.br/site/wp-

content/uploads/2010/05/microsoft-powerpoint-fgv-ap-minc-completa79.pdf $>$. Acesso em: 03 mar. 2016. 
CUNHA, M. B.; CAVALCANTI, C. R. O. Dicionário de Biblioteconomia e Arquivologia. Brasília: Briquet de Lemos, 2008.

DIAS, G. D.; SILVA, T. E.; CERVANTES, B. M. N. Política de desenvolvimento de coleções para documentos eletrônicos: tendências nacionais e internacionais. Encontros Bibli, Florianópolis, v. 17, n.34, p. 42-56, 2012. Disponível em:

<http://www.periodicos.ufsc.br/index.php/eb/article/view/15182924.2012v17n34p42/22652>. Acesso em: 28 fev.2016.

Políticas de informação nas bibliotecas universitárias: um enfoque no desenvolvimento de coleções. Revista Digital de Biblioteconomia e Ciência da Informação, Campinas, v.11, v.1, p. 39-54, 2013. Disponível em: <http://www.sbu.unicamp.br/seer/ojs/index.php/rbci/article/view/572>. Acesso em 05 mar. 2016.

DIAS, M. M. K.; PIRES, D. Formação e desenvolvimento de coleções de serviços de informação. São Carlos: EdUFSCar, 2003.

FIGUEIREDO, N. M. Metodologias para a promoção do uso da informação: técnicas aplicadas particularmente em bibliotecas universitárias e especializadas. São Paulo: Nobel, 1991.

FEDERAÇÃO INTERNACIONAL DE ASSOCIAÇÕES DE BIBLIOTECÁRIOS E BIBLIOTECAS. Diretrizes da IFLA para bibliotecas públicas. Brasília: Briquet de Lemos, 2012.

FREITAS, M. A. de; SILVA, V. B. da. Bibliotecas públicas brasileiras: panorama e perspectivas. Revista Digital de Biblioteconomia e Ciência da Informação, Campinas, v.12, n.1, p.123146, 2014. Disponível em: <file:///D:/Documents\%20and\%20Settings/f156991/Meus\%20documentos/Downloads/3 890-8558-2-PB\%20(1).pdf>. Acesso em: 01 fev. 2016.

LANCASTER, F. W. Avaliação de serviços de bibliotecas. Brasília: Briquet de Lemos, 1996.

MACHADO, F. B.; SUAIDEN, E. J. O papel da biblioteca pública e seus desafios frente aos avanços tecnológicos. In: CONGRESSO BRASILEIRO DE BIBLIOTECONOMIA, DOCUMENTO E CIÊNCIA DA INFORMAÇÃO, 25., 2013, Florianópolis. Anais eletrônicos... Florianópolis, FEBAB, 2013. Disponível em:

<file:///D:/Documents\%20and\%20Settings/f156991/Meus\%20documentos/Downloads/1 284-1297-1-PB\%20(2).pdf>. Acesso em: 20 jan. 2016.

MILANESI, Luís. 0 que é biblioteca. São Paulo: Brasiliense, 1983. (Coleção Primeiros Passos. n. 94).

MILANESI, Luís. Biblioteca Pública: do século XIX para o XXI. Revista USP, São Paulo, n. 97, p. 59-70, 2013.

MIRANDA, A. C. C. de. Formação e desenvolvimento de coleções em bibliotecas especializadas. Informação \& Sociedade: estudos, João Pessoa, v.17, n.1, p.87-94, 2007. Disponível em: <http://www.ies.ufpb.br/ojs/index.php/ies/article/view/463>. Acesso em: 03 jan. 2016.

Desenvolvimento de coleções em bibliotecas universitárias. Revista Digital de Biblioteconomia e Ciência da Informação, Campinas, v.4, n.2, p. 1-19, 2007. Disponível em: <http://www.sbu.unicamp.br/seer/ojs/index.php/rbci/article/view/367/246>. Acesso em 153 jan. 2016.

A política de desenvolvimento de coleções no âmbito da informação jurídica. In: PASSOS, Edilenice (Org.). Informação jurídica: teoria e prática. Brasília: Thesaurus, 2004. 
MULLER, Suzana Pinheiro Machado. A ciência, o sistema de comunicação científica e a literaturac ientífica. In: CAMPELO, Bernadete Santos (Org.). Fontes de informação para pesquisadores e profissionais. Belo Horizonte: UFMG, 2000.

LE COADIC, Yves-François. A ciência da informação. 2. ed. Brasília: Briquet de Lemos, 2004.

PRADO, H. A. Organização e administração de bibliotecas. São Paulo: T. A. Queiroz. 1992.

SANTOS, M. P.; SANTOS, C. A. da S.. Bibliotecas Públicas no século XXI: uma releitura da literatura. CRB-8 Digital, São Paulo, v. 5, n. 2, p. 10-16, dez. 2012. Disponível em: <http://revista.crb8.org.br/index.php/crb8digital/article/viewFile/89/89>. Acesso em: 30 jan. 2016.

SILVA, R. A. da. E-books em bibliotecas: novos desafios para os bibliotecários. In: CONGRESSO BRASILEIRO DE BIBLIOTECONOMIA, DOCUMENTO E CIÊNCIA DA INFORMAÇÃO, 25., 2013, Florianópolis. Anais eletrônicos... Florianópolis, FEBAB, 2013. Disponível em: <file:///D:/Documents\%20and\%20Settings/f156991/Meus\%20documentos/Downloads/1 398-1411-1-PB.pdf>. Acesso em: 29 jan. 2016.

SILVA, V. B. Biblioteca pública brasileira: panorama, perspectivas e a situação do Distrito Federal. 2013. 104 f. Dissertação (Mestrado em Ciências da Informação)- Programa de Pós-Graduação em Ciência da Informação da, Universidade de Brasília, Brasília, 2013.

SUAIDEN, E. J. Biblioteca pública brasileira: desempenho e perspectivas. São Paulo: Livros Irradiantes S.A., 1980.

VERGUEIRO, V. C. S. Desenvolvimento de coleções. São Paulo: Polis, 1989.

WEITZEL, S. da R. Elaboração de uma política de desenvolvimento de coleções em bibliotecas universitárias. Rio de Janeiro: Interciência, 2006.

Editores do artigo: Adilson Luiz Pinto, Rafaela Paula Schmitz e Enrique Muriel-Torrado 